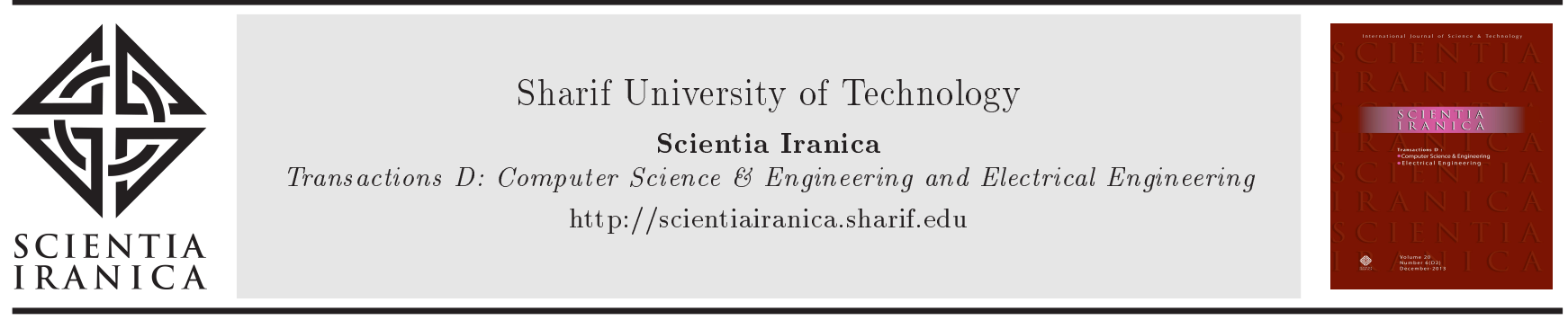

\title{
An incentive-based policy on minimization of GHG emissions and loss using adaptive group search multi-objective optimization algorithm
}

\author{
M.H. Nazari ${ }^{\mathrm{a}}$, S.H. Hosseinian ${ }^{\mathrm{a}, *}$, E. Azad Farsani ${ }^{\mathrm{b}}$, and D. Faramarzi ${ }^{\mathrm{a}}$ \\ a. Department of Electrical Engineering, Amirkabir University of Technology, Tehran, Iran. \\ b. Department of Electrical Engineering, Golpaygan University, Golpaygan, Iran.
}

Received 9 June 2019; received in revised form 1 August 2019; accepted 2 September 2019
KEYWORDS
Incentive-based method;
Energy pricing;
Modern distribution
network;
Multi-objective
optimization;
Loss reduction;
Emission mitigation.

\begin{abstract}
A transactive strategy for purposeful pricing of Distributed Energy Resources (DERs) in distribution networks is proposed in this paper. This strategy is presented as a novel heuristic optimization approach. Reduction of both total network loss and released greenhouse gases (GHGs) emissions can be considered as the intended objective functions. In addition, Locational Marginal Pricing (LMPs) and power factors associated with DERs are considered as decision variables. Each DER, which is more involved in the mitigation of the aforementioned objectives, gives rise to greater benefits in the long term. Therefore, such a contribution to greater generation on a large scale leads to the higher price of using DER bus than substation market price. Also, the benefits earned from loss/emission mitigation are allocated to DERs directly. The fairness of this pricing process is supervised by the Independent Distribution System Operator (IDSO). Given that the problem has two contradictory objective functions, a reliable Multi-objective Group Search Optimization utilizing Covariance matrix and Chaotic search (MGSOACC) is proposed to solve the problem. To evaluate the viability of the proposed method, the pricing procedure is applied to modified IEEE-33 and IEEE-69 bus test networks. Furthermore, to validate the proper functionality of the proposed optimization method, result-oriented comparisons between four conventional multi-objective optimization methods and the proposed optimization method are made.
\end{abstract}

(C) 2022 Sharif University of Technology. All rights reserved.

\section{Introduction}

Reducing emission from the generation of electrical energy and alleviating its environmental and economic impacts, especially $\mathrm{CO}_{X}$, has become one of the most important issues in event researches on this subject

\footnotetext{
*. Corresponding author. Tel.: +98216454 3343;

Fax: +982164543301

E-mail address: hosseinain@aut.ac.ir (S.H. Hosseinian)
}

$[1,2]$. Also, having been considered by a large number of branches and feeders in distribution networks as well as the high contribution of these networks to total loss, loss and emission reduction is considered as one of the most important challenges in the operation and planning of these networks [3].

The conventional methods used for reducing loss and emission in distribution networks generally require budget extension, add/remove equipment, and network reconfiguration. In the method proposed in this paper, not only is there no need to add/remove equipment or change the network configuration, but 
also no additional charges are imposed on the network. Therefore, operators prioritize this approach over other existing options.

From this point of view, use of Distributed Energy Resources (DERs) can become an effective alternative to provide a good solution to distribution issues. DERs in Micro Grids (MG) are planned and sized to reduce the total electrical loss [4], transmission loss [5], and thermal loss [6]. Many types of research have focused on the mitigation of emission in distribution networks [7]. DERs are employed to mitigate the loss incurred by distribution networks upon changing the flow of the feeders [8]. Unlike conventional thermal power, DERs often use renewable energy, natural gas, or other clean energies, which can be more efficient in the emission problem.

Conventional methods carry out the process of reducing loss by usually removing/adding equipment [3], or by changing the network configuration [3] . In addition, in many other studies, the process of planning to reduce losses takes place before network implementation or for a long-term period [9]. In a similar manner, in order to reduce Greenhouse gases (GHGs) emission, conventional methods are based on the addition of expensive equipment such as filters. However, the proposed method reduces emission and loss without making any changes to network configuration, adding/removing equipment, or imposing additional costs on the network.

On the other hand, the proposed method can also be applied to the network in the operation mode and does not require long-term research to modify the network. Conventional pricing methods in the power markets include uniform [10], zonal [11], marginal loss [12], and Locational Marginal Pricing (LMP) [13]. Uniform method considers a single price for all nodes on networks. Therefore, this method cannot be useful for purposeful pricing approaches. Several prices with one price for all nodes in any given zone is called the zonal price [11]. In the zonal approach, the market is divided by the congested interconnector. There needs to be either an organized market with a separate price on each side of the interconnector or two closely co-operating power exchanges. With marginal loss pricing, transmission losses are priced according to marginal loss factors. The marginal loss factor at a bus is the increase in the percentage of system losses caused by a small increase in power injection or withdrawal at the bus. Marginal loss factors are always twice the average loss factors. However, this pricing method results in the significant accumulation of loss revenues. Therefore, the fairness of this method in the settlement of incentives and benefits may not be guaranteed [12]. Locational marginal pricing is a way for wholesale electric energy prices to reflect the value of electric energy at different locations, accounting for the patterns of load, generation, and physical limits of the transmission system [14]. The revenue settlement can be performed perfectly.

Locational marginal pricing is one of the most effective methods for energy pricing to demonstrate the economic impact of each bus on the network. Many of the world's most reliable electricity markets, including PJM, MISO, and NYISO, have employed this pricing method for their transactions [15].

The locational marginal pricing [16] method, in comparison with other conventional pricing methods [17], is a well-known strategy in electricity market transactions, because it can reflect the impact of power flows and contingency problem in branches of the networks. This method has the ability to absorb the technical nature of the network in the economic considerations by making a change in the fair price of each region depending on technical conditions.

On the other hand, DERs can be beneficial in dealing with financial operational problems such as energy pricing. In recent years, some methods have been developed for solving the electricity pricing problems at DER buses. The locational marginal pricing problem is considered in the presence of demand response [18]. A game theoretic method for calculation of locational marginal pricing in distribution networks was presented in [19]. The network congestion, loss, and technical limits such as bus voltage limits were considered to determine the LMP [20]. The fuzzy-based method was proposed for the hour-ahead electricity market in [21]. In [22], a new method was presented for optimal DER placement with the nodal pricing by considering profit, loss reduction, and voltage improvement.

The pricing procedure of these researches is characterized by important features; however, they have not considered the following important features that are considered in this paper:

- They do not consider the other technical factors, including emission, in the LMP calculation;

- The guaranteed non-mandatory method for the involvement of DERs in the realization of network objectives is not considered, because all these methods are implemented based on a mandatory approach;

- The ability of decision-makers to deal with the system priority among the different objectives such as losses/emission reduction and DER unit's profit is not considered;

- Comprehensive comparisons between the performances of conventional optimization methods including MOGA, MOPSO, NSGA-II, and MOPSOFDR with that of the proposed optimization method were made in terms of the best and worst solutions, average solution, and standard deviation.

In this paper, the locational marginal pricing 
problem is presented in conjunction with a Multiobjective method using Group Search Optimizer with Adaptive Covariance matrix and Chaotic search (MGSOACC) [23] with consideration of the abovementioned features to reduce the total loss and emission of the network. In addition, decision variables are LMPs at DER busses and power factor of DERs. Since the considered problem refers to the simultaneous optimization of two interconnected objectives, i.e., losses and emission, a multi-objective algorithm is used to obtain Pareto set solutions during the search process and store them in a repository. Because the objective functions are not the same in terms of size and dimension, the size of the repository is controlled using a fuzzy clustering technique [24].

The remainder of this paper is divided into 3 sections: the first part of Section 2 explains the loss and emission formulation and calculation. The remainder of Section 2 shows reduction of loss and emission for the multi-objective problem and the proposed algorithm. Section 3 provides simulation results to confirm the effectiveness of the proposed method. Finally, Section 4 presents the conclusion of the paper. A schematic diagram of the pricing procedure, simulation, and the connection between sections, figures, and tables of the manuscript is presented in Figure 1.

\section{Formulation of the incentivization problem}

The formulation of loss and emission in terms of cost function is expressed in the first part of this section. Then, the constraints of the optimization problem and multi-objective considerations are presented.

\subsection{Cost function}

Two main objectives of the distribution network operation are loss and emission reduction and DERs can affect them drastically. In this paper, LMP for DERconnected busses is calculated based on the behavior of the corresponding DER in the mitigation of loss and emission. The cost functions are measured through Eqs. (1) and (2):

$P_{\text {loss }}(X)=\sum_{b r=1}^{N_{b r}} R_{b r}\left|I_{b r}\right|^{2}$

$x \in X$,

$\left\{\begin{array}{l}E=\sum_{i=1}^{N_{D G}} E_{D G, i}+E_{G r i d} \\ E_{\text {grid }}=\left(E_{G r i d}^{N O x}+E_{G r i d}^{S O_{2}}+E_{G \text { rid }}^{C O_{2}}+E_{G r i d}^{C O}\right) \times P_{G r i d} \\ E_{D G, i}(X)=\left(E_{D G, i}^{N O x}+E_{D G, i}^{S O_{2}}+E_{D G, i}^{C O_{2}}+E_{D G, i}^{C O}\right) \times P_{D G, i}\end{array}\right.$

$x \in X$

In addition, the vector-valued objective function and control variables are defined as Eqs. (3a) and (3b), respectively:

$$
f: X \rightarrow \mathbb{R}^{k} ; f(x)=\left(f_{1}(x), f_{2}(x)\right),
$$

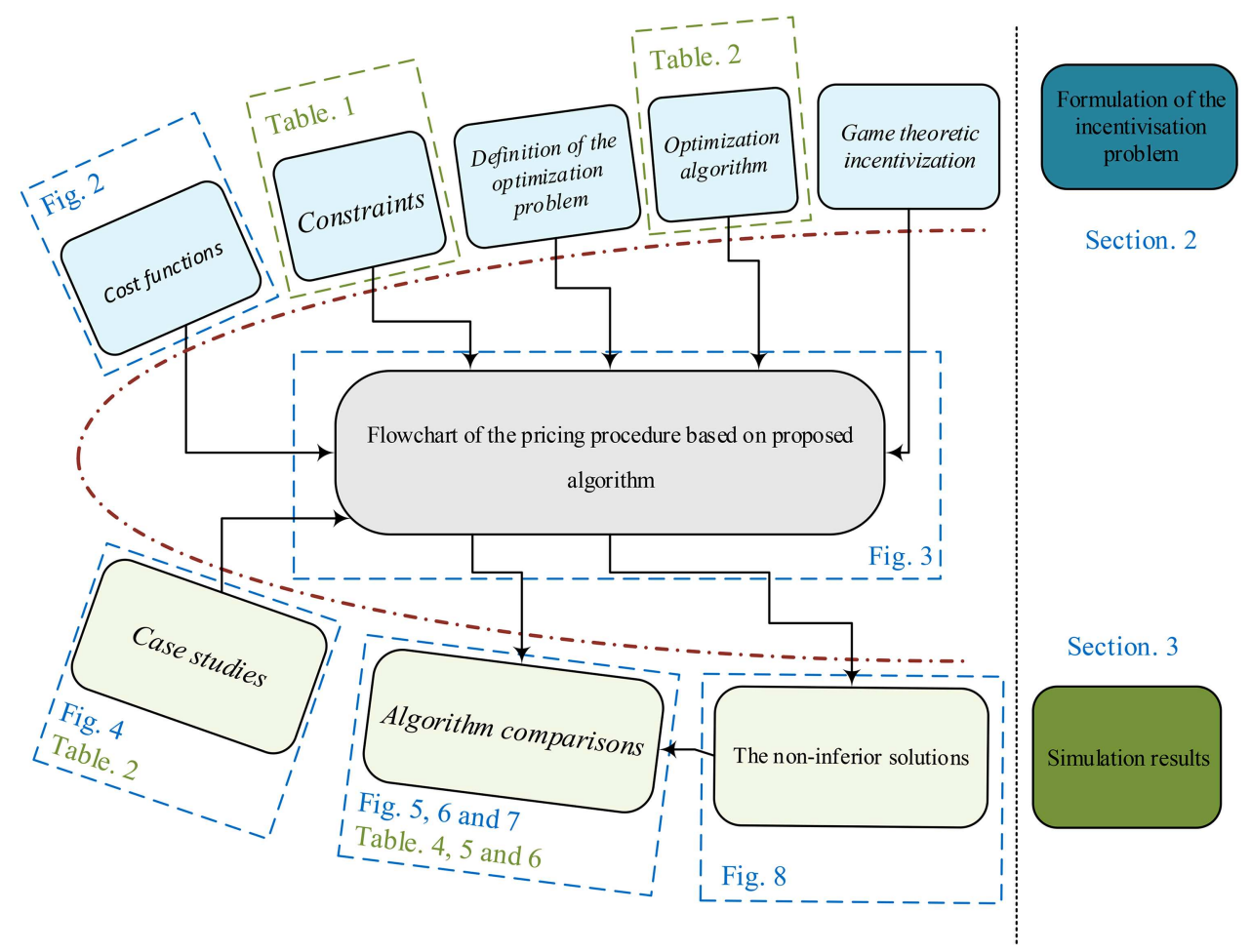

Figure 1. Schematic diagram of the paper. 


$$
X=\left[\pi_{1}, \pi_{2}, \ldots, \pi_{i}, \ldots, \pi_{N_{D G}}, p f_{1}, p f_{2}, \ldots p f_{i}, \ldots, p f_{N_{D G}}\right]
$$

where $X$ is the control variable vector in the LMP calculation problem in DER-connected busses.

Further, since the proposed method is multiobjective, each objective cannot be weighed in accordance with Eq. (4):

$$
\omega_{1} f_{1}(x)+\omega_{2} f_{2}(x) \text {. }
$$

However, if the operators need to prioritize, they can prioritize the incentives in the pricing process instead of prioritizing each objective function.
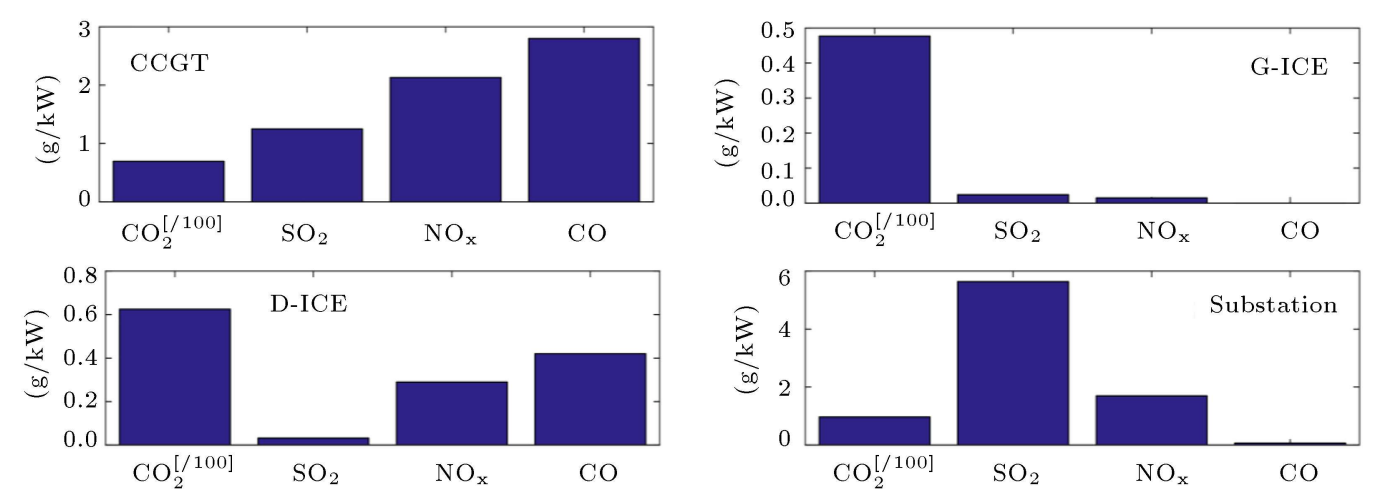

Figure 2. Emission coefficients of substation bus and Distributed Energy Resource (DER) units.
Furthermore, the values of emission coefficients of substation bus and DER units are presented in Figure 2 [19].

\subsection{Constraints}

Limitations and constraints associated with the pricing problem interconnected with the power flow problem can be classified into two categories: equalities and inequalities. The constraints on the optimization of the aforementioned cost functions are categorized, as can be seen in Table 1. Limitations and constraints in the case of the load flow problem can be classified into two categories: equalities and inequalities.

\begin{tabular}{|c|c|c|}
\hline \multicolumn{3}{|c|}{$\begin{array}{l}\text { Inequality constraints in the form of } \\
\qquad H(x, u, y) \geq 0\end{array}$} \\
\hline Active and reactive & $P_{\min , D G, i} \leq P_{D G, i} \leq P_{\max , D G, i}$ & \\
\hline power limitations & $Q_{\min , D G, i} \leq Q_{D G, i} \leq Q_{\max , D G, i}$ & $(5)$ \\
\hline $\begin{array}{l}\text { Constraints through operating } \\
\text { limits on flows }\end{array}$ & $\left|F_{i j}\right| \leq \overline{F_{i j}}$ & (6) \\
\hline $\begin{array}{l}\text { Constraints through operating } \\
\text { limits on voltages }\end{array}$ & $\underline{V_{j}} \leq V_{j} \leq \overline{V_{j}}$ & (7) \\
\hline $\begin{array}{l}\text { Constraints through power } \\
\text { factor consideration }\end{array}$ & $P f_{\min , i} \leq P f_{i} \leq P f_{\max , i}$ & (8) \\
\hline $\begin{array}{l}\text { Constraint on Merchandising } \\
\text { Surplus (MS) }\end{array}$ & $M S=\left[\begin{array}{c}\lambda\left(\text { loss }^{\text {base }}-\text { loss }\right)+\gamma_{t} \omega_{e}\left(\text { emission }^{\text {base }}-\text { emission }\right)- \\
\sum_{i=1}^{N_{D G}}\left(\pi^{r}\right)_{i}\left(Q_{D G, i}\right)-\sum_{i=1}^{N_{D G}}\left(\left(\pi^{a}\right)_{i}-\lambda\right)\left(P_{D G, i}\right)\end{array}\right.$ & (9) \\
\hline & $M S \leq \varepsilon$ & $(10)$ \\
\hline \multicolumn{3}{|c|}{$\begin{array}{l}\text { Equality constraints in the form of } \\
\qquad G(x, u, y)=0\end{array}$} \\
\hline Power balance constraint & $\sum_{d=1}^{N_{D E R}} P_{D E R_{d}}+P_{S u b}-\sum_{i=1}^{N_{b}} P_{D_{i}}=0$ & $(11)$ \\
\hline
\end{tabular}

Table 1. Constraints and limitations of the optimization problem. 
As the loss/emission reduced by DER units is minimized, the benefit of the Distribution Company (DISCO) increases.

Considering the role of DERs in meeting the network objectives and in line with the minimization of emission and loss, the profit of DISCO is increased. This increase is formulated in Eq. (9) in Table 1 [25].

The Merchandising Surplus (MS) is greater than zero and must be minimized in a fair competition generally. Therefore, the constraints on MS are considered as Eq. (10), where $\varepsilon$ is the maximum deviation of the MS. The details of this constraint were presented in [26].

\subsection{Definition of the optimization problem}

For solving a minimization problem using the interval approach, $C_{1}$ (interval number) is considered to be more proper than interval number $C_{2}$ if the center point and radius of $C_{1}$ are smaller than those of $C_{2}$, i.e., $c\left(C_{1}\right)<c\left(C_{2}\right)$ and $r\left(C_{1}\right)<r\left(C_{2}\right)$. Thus, the center point and the radius should be minimized. This procedure leads to the formulation of the problem into a standard multi-objective problem.

In this paper, the objective deviation and average are considered as dual conflicting objectives to attain a trade-off between them, in which the weighting factor is not required essentially.

The objective deviation and average are formulated in terms of the radius and center point of the objective interval in Eq. (12):

$$
\begin{aligned}
& c(C(X, Y, Z))=\frac{1}{2}\left(C^{L}(x)+C^{R}(x)\right), \\
& c(C(X, Y, Z))=\frac{1}{2}\left(C^{L}(x)+C^{R}(x)\right),
\end{aligned}
$$

where $c$ and $r$ are the values of the center point and radius, respectively; $C^{R}(x)$ and $C^{L}(x)$ are the upper and lower bounds of the interval corresponding to a specific independent variable $X$. Then, these parameters can be obtained by solving the sub-problems in Eq. (13):

$$
\begin{aligned}
& C^{L}(x)=\min _{U}(C(X, Y, Z)), \\
& C^{R}(x)=\max _{U}(C(X, Y, Z)) .
\end{aligned}
$$

Once the upper and lower bounds of objective intervals are determined, the deviation and average of the objective interval are calculated using Eq. (9) by considering its upper and lower bounds. By inserting Eq. (13) into Eq. (12), the multi-objective optimization problem is formulated. This formulation is presented in Eq. (11):

$$
\begin{array}{ll}
\min [ & m(C(X, Y, Z), r(C(X, Y, Z))] \\
\text { s.t. : } c\left(C(X, Y, Z)=\frac{1}{2}\left(\min _{Z} C(X, Y, Z)\right.\right. \\
\left.\quad+\max _{Z} C(X, Y, Z)\right), \\
\quad r(C(X, Y, Z))=\frac{1}{2}\left(\min _{Z} C(X, Y, Z)\right. \\
\left.\quad-\max _{Z} C(X, Y, Z)\right), \\
g(X, Y, U)=0, \\
h(X, Y, U) \leq 0 \\
Z \in\left[Z^{L}, Z^{R}\right] .
\end{array}
$$

Also, Eq. (14) is a two-stage optimization problem that contains a first-stage problem for optimizing $c$ and $r$ and is also a dual-stage nonlinear problem for determining the objective interval bounds. This optimization is presented in the next part of this section.

\subsection{Optimization algorithm}

The producers, rangers, and scroungers constitute the main group members of the MGSOACC, respectively. The number of the first group is equal to that of the objectives, and each member of this group corresponds to the best fitness value of the predefined objective in each search generation. The first group members are scanning the search area employing white crappie's scanning strategies [27] to search for the optimal source. The third group is affiliated with the adaptive covariance matrix [28] to make the search approach for the third group members be adaptive. It leads to getting a dependable estimator for the paths. Therefore, it could improve the local search capability of the proffering method [27].

Furthermore, the chaotic search is used as the search approach of the second group to save the diversity of the members. Also, the chaotic sequence is presented based on the logistic map [28].

$$
u^{(k+1)}=\mu \cdot u^{(k)} \cdot\left(1-u^{(k)}\right)
$$

where $u^{(g)} \in[0,1] \therefore u^{(0)} \notin\{0,0.25,0.5,0.75,1\}$ and $g$ is the $k$ th iteration.

Then, the position of the $i$ th member of the second group is updated based on the chaotic search in Eq. (13).

$$
x_{i}^{(k+1)}=x_{i}^{(k)}+u^{(k)} \cdot\left(x_{i}^{(k)}-\wp_{i}\right),
$$

where $\wp_{i}$ donates the optimal Pareto front which is derived from Pareto set with random selection. The pseudo-code of the optimization method is presented in Table 2. 
Table 2. Constraints and limitations of the optimization problem.

Set $k=1$;

Input the DERs characteristics, line impedance, and emission coefficients;

Initialize parameters of each member of triple groups of MGSOACC;

Determine the bounds of objective intervals by non-linear programming using Eq. (13);

Obtain the lower and upper bounds of the objective interval of each member by non-linear programming using Eq. (13);

Calculate the fitness values of initial members using Eq. (14);

WHILE (the termination conditions are not met)

FOR (each member in the group)

Choose

Select producers from the group. The number of producers is equal to the

Chose number of objectives. The member with the best fitness value of the $p$ th objective is selected as the producer;

Each producer scans at zero degree and then, scan laterally by randomly sampling three points in the scanning field using Eqs. (5) to (9)

Producers perform in $[27]$;

producing:

Perform scrounging: Except the producers, randomly select $70 \%$ from the rest members to perform scrounging:

1) Generate mean vector by exponential weighting [28]

2) Update covariance matrix to determine evolution path and update step-size using Eq. (30) in Ref. [37]

Perform ranging Except the producers and scroungers, the rest members perform ranging:

1) Generate the chaotic sequence using Eq. (14)

2) Rangers perform chaotic search using Eq. (14)

Update group Select new producers and generate new group members

\section{END FOR}

Calculate fitness

Pareto selection

Update the Pareto solutions using fast non-dominated sorting technology and fix the number of elements in the Pareto solution set as a constant by the crowded comparison operator [38]

1) Obtain the lower and upper bounds of the objective interval of each current member by non-linear programming using Eq. (13)

2) Calculate the fitness values of current members using Eq. (14)

$\mathrm{g}=\mathrm{g}+1$ 


\subsection{Game-theoretic incentivization}

The contribution of each Distributed Generation (DG) to incentives should be guaranteed in a fair approach. One of the proper methods for fair allocation of incentives to participants is cooperative game-theoretic methods, e.g., Shapley value $[29,30]$. In this paper, each DG is examined as a player. The objective of this game is earning much profit by players due to their participation in satisfying the network's objectives and reducing loss and emission. In this paper, the Shapley value method is utilized. In the conventional Shapley value, for $n$ players, the total set of $2^{n}-1$ coalitions should be evaluated and this manner carries a high computational burden. Therefore, in this paper, instead of the CSV method, the Aumann-Shapley value method is employed with lower computational burden for allocating loss reduction and emission to each DG. $N$ is considered as all players (DGs) set coalition for $n$ players. $S$ is considered as a subset of $N$ and $|S|$ is the number of players in the $S$ coalition. In this case, Shapley value is presented for the first objective, loss, related to player $i$ in all $N^{\prime}$ 's in Eqs. (17) to (25) [31]:

$$
\begin{gathered}
\phi_{i}(v)=\sum_{\substack{s \subseteq N \\
i \in S}} \frac{(|S|-1) !(n-|S|) !}{n !} \\
{[v(s)-v(s-\{i\})] .}
\end{gathered}
$$

If $N_{R}$ and $N_{I}$ are considered as the real and imaginary parts of branch currents, respectively, then we have:

$$
\begin{aligned}
& N_{R}=\left\{I_{1 r}+\ldots+I_{i r}+\ldots+I_{n r}\right\}^{2}, \\
& N_{I}=\left\{I_{1 i}+\ldots+I_{i i}+\ldots+I_{n i}\right\}^{2} .
\end{aligned}
$$

The electrical loss is calculated through Equation (19).

$$
\operatorname{Loss}_{r}\left(I_{i}\right)=r \cdot\left\{I_{1 r}+\ldots+I_{i r}+\ldots+I_{n r}\right\}^{2} .
$$

In this case, the unit's Aumann-Shapley partnership index is presented in Eq. (20):

$$
\begin{aligned}
\operatorname{Loss}_{r}\left(I_{i}\right) & =\int_{t=0}^{1} \frac{\partial S_{L}\left(t I_{i}\right)}{\partial I_{i r}} d t \\
& =\int_{t=0}^{1} 2\left[\left(I_{1 r}+\ldots+I_{i r}+\ldots+I_{n r}\right) t\right] \cdot r d t \\
& =r \cdot\left\{I_{1 r}+\ldots+I_{i r}+\ldots+I_{n r}\right\} .
\end{aligned}
$$

Therefore, the reduced loss can be obtained using Eq. (21):

$$
v_{l}(s)=\text { Loss }_{r}^{\text {without } D G}-\operatorname{Loss}_{r}^{\text {with } D G} .
$$

Thus, the allocation of active loss to player $i$ from the currents of branches is shown in Eq. (22):

$$
A L R_{i}=\pi_{I_{i r}} \cdot I_{i r}=I_{i r} \cdot\left\{I_{1 r}+\ldots+I_{i r}+\ldots+I_{n r}\right\} \cdot r .
$$

Nevertheless, in this paper, the main objective is to allocate loss and emission to players simultaneously. According to this fact, the $W(|S|)$ for the cooperative game should be defined. The $\left[v_{r}(s)-v_{r}(s-d)\right]$ represents the contribution of each DG to the reduction of loss; and the $\left[v_{e}(s)-v_{e}(s-d)\right]$ represents this contribution to emission compared to the base status (without purposeful participation of DGs) [31]:

$$
W(|s|)=\frac{\left(N_{D G}-|s|\right) ! \times(|s|-1) !}{N_{D G} !} .
$$

For the emission index, a process is similar to Eq. (21). By analogy, the same process is considered for this objective in Eq. (21):

$$
v_{l}(s)=T H D^{\text {without } D G}-T H D^{\text {with } D G} .
$$

Thus, the contribution of each DG from incentives corresponding to loss and emission reduction in the form of $\left(A L R_{d}\right)$ and $\left(A E R_{d}\right)$ is determined as follows:

$$
\begin{aligned}
& A L R_{d}=\sum_{d \in s} W(|s|) \times\left[v_{r}(s)-v_{r}(s-d)\right], \\
& A E R_{d}=\sum_{d \in s} W(|s|) \times\left[v_{e}(s)-v_{e}(s-d)\right],
\end{aligned}
$$

where $v_{r}(s)-v_{r}(s-d)$ expresses the amount of loss reduced by DG no. $d$, subtracted from the total loss reduced by all-player set coalitions and $v_{e}(s)-v_{e}(s-d)$ indicates the value of emission index mitigated by DG No. $d$, subtracted from the emission mitigation of allplayer set coalitions.

Upon using this procedure, the fairness of the pricing method is guaranteed based on the cooperative game-theoretic method [32]. Further, the flowchart of the pricing procedure based on the proposed algorithm is presented in Figure 3.

\section{Simulation results}

\subsection{Case studies}

The multi-objective LMP calculation in distribution networks is tested on the IEEE 33 bus distribution and IEEE 69-bus distribution test system with four and nine DERs, respectively. The IEEE 33-bus test system is a $12.66 \mathrm{kV}$ system including a substation, two feeders, and 33 buses. The IEEE 33-bus test system data were given in [1], and the single-line diagram of this system is shown in Figure 2. The initial loss of the network is $202.47 \mathrm{~kW}$ and the initial emission is $3617.365 \mathrm{~kg}$. for the DER units which are placed in $5,11,25,30$ buses. 


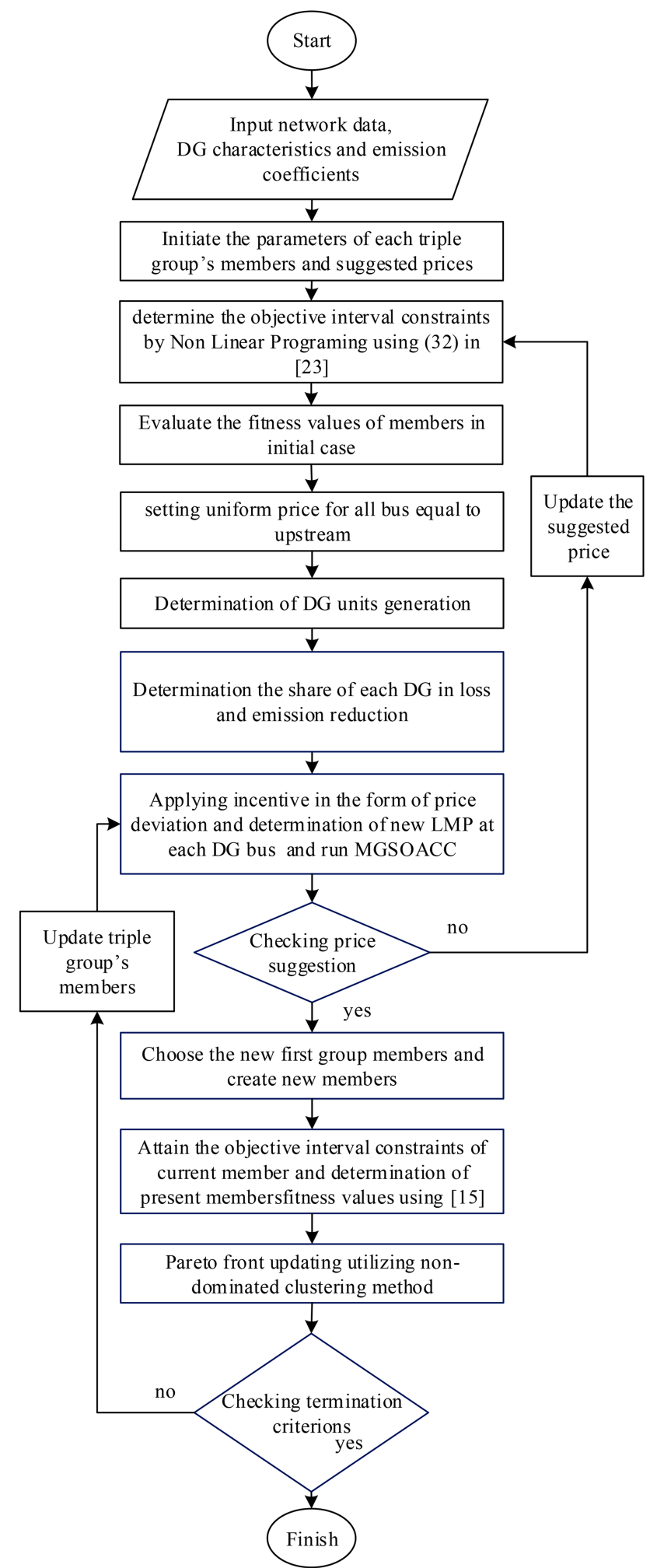

Figure 3. Flowchart of the pricing procedure based on the proposed algorithms.

The IEEE 69 bus test system consists of 69 nodes, 5 looping lines, and 7 lateral feeders. The total demands of the system are $3802.19 \mathrm{~kW}$ and $2694.60 \mathrm{kVAr}$, respectively, with the system voltage of
$12.66 \mathrm{kV}$ [2]. The initial and emission losses of the network are $655.23 \mathrm{~kW}$ and $7521.514 \mathrm{~kg}$, respectively [3]. The single diagram of IEEE 33 bus and IEEE 69 bus networks are presented in Figure 4(a) and (b), respectively.

Emission coefficients for these DERs are shown in Figure 2 and Table 3 . In addition, the cost functions of DER units in terms of coefficients $a, b$, and $c$ are presented in Table 3.

\subsection{Algorithm comparisons}

First, to evaluate the superiority of the MGSOACC algorithm to MOPSO [33], MOPSO-FDR, MOGA [34], and NSGA-II [35] algorithms as well as the loss and emission were optimized by using these three aforementioned algorithms separately. The pseudocode of this algorithms is described in Table 4 [3336]. In this comparison, the market price is equal to $28 \$ / \mathrm{MW}$. Figure 5(a) presents the competitive results of MOPSO, MOGA, and MGSOACC algorithms in case when loss is considered as the objective function for the IEEE 34-bus network. Also, in Figure 5(b), the results of algorithms are presented considering that emission is the objective function for the IEEE 34 bus network. In addition, the competitive simulation results of the five aforementioned algorithms for IEEE 69 bus network are presented in Figure 6(a) and (b). As shown in Figures 5 and 6, the results of MGSOACC algorithm are much more reliable than other optimization algorithms. This superiority may result in the greater reduction of loss and emission.

The results of the proposed MGSOACC algorithm derived from LMP calculation are presented in Tables 5, 6, and Figure 7. In these tables, the proposed method is compared with the other two conventional LMP calculation methods, namely uniform price method and marginal losses method [17]. In Tables 5 and 6, DER units' nodal price and their generation for different market prices are presented, and the results of these three methods are compared. As the market price increases, the generation of DERs and nodal price increase using all the three methods.

In fact, the generation of DERs is adjustable with a new nodal price; however, generation and price of DERs for the proposed method are more than marginal losses and uniform price methods. In comparison with other conventional methods, the greater active power of DERs and the high price of DER connected buses point to the efficiency of this method. Given that the higher generation of DERs causes lower loss and emission, we can approach our aim, e.g., reducing the mentioned objectives. For starting the DERs, coefficient ' $b$ ' in Eq. (15) must be lower than market price.

As shown in Table 5, for the market price equal to $20(\$ / \mathrm{MW})$, all DERs are turned off and do not yield any generation. When the DER is turned off and 


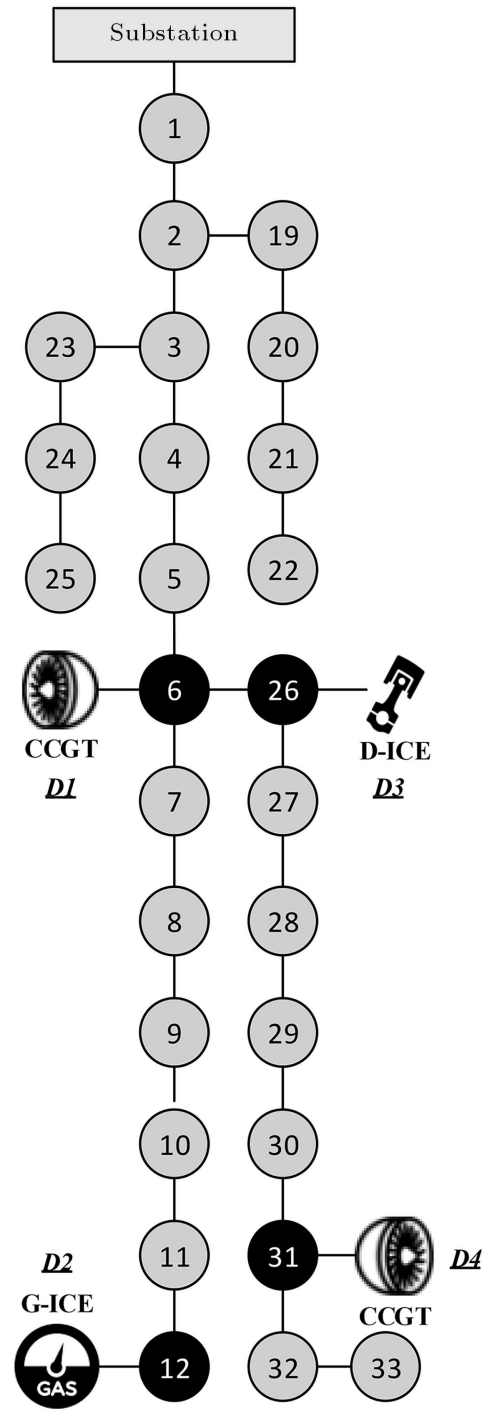

(a)

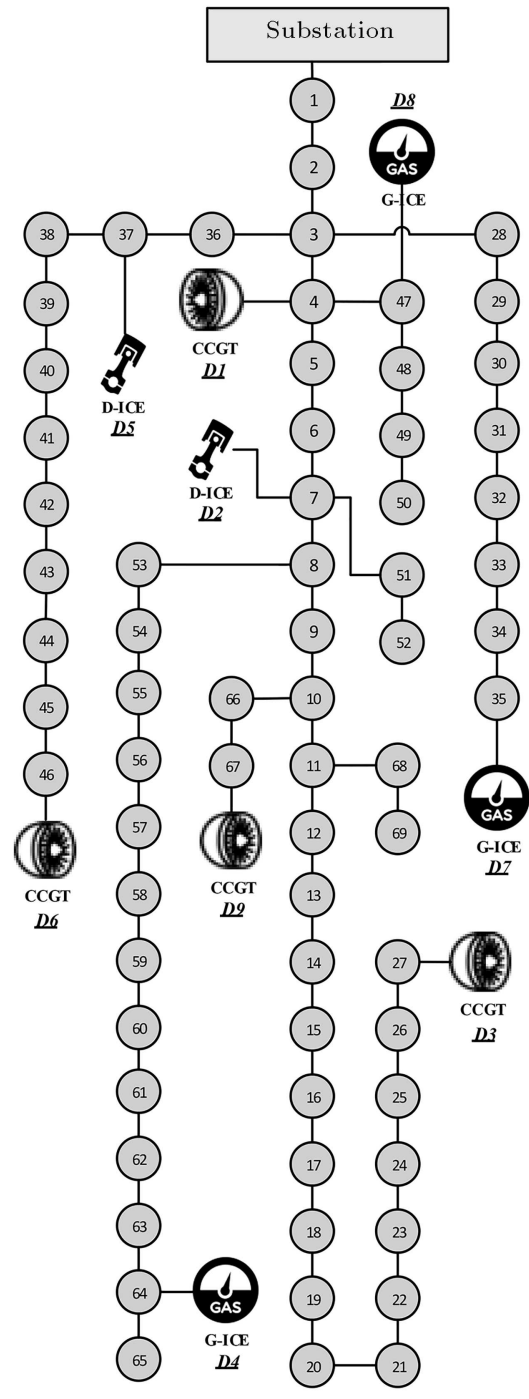

(b)

Figure 4. Single line diagram of 33- and 69- bus distribution test systems.

Table 3. Economic characteristics and emission coefficients of Distributed Energy Resources (DERS).

\begin{tabular}{cccccccccc}
\hline & & \multicolumn{2}{c}{$\begin{array}{c}\text { Economic } \\
\text { Characteristics } \\
\text { of DERs }\end{array}$} & \multicolumn{5}{c}{$\begin{array}{c}\text { Emission coefficients } \\
\text { of DER units } \\
\text { and the upstream bus }\end{array}$} \\
\hline No. DER & Type & $\begin{array}{c}\text { Capacity of } \\
\text { DER }(\mathbf{k W})\end{array}$ & $\begin{array}{c}\boldsymbol{a} \\
\left(\$ / \mathbf{M W}^{2}\right)\end{array}$ & $\begin{array}{c}\boldsymbol{b} \\
(\$ / \mathbf{M W})\end{array}$ & $\begin{array}{c}\boldsymbol{c} \\
(\$)\end{array}$ & $\mathbf{C O}_{2}$ & $\mathbf{S O}_{2}$ & $\mathbf{N O x}$ & $\mathbf{C O}$ \\
\hline $\mathbf{D E R}_{1}$ & CCGT & 1000 & $5.8 \times 10^{-6}$ & 0.021 & 0 & 695 & 1.25 & 2.13 & 2.8 \\
$\mathbf{D E R}_{4}$ & & 1000 & $5.3 \times 10^{-6}$ & 0.020 & 0 & 477 & 0.024 & 0.015 & 0 \\
$\mathbf{D E R}_{2}$ & G-ICE & 1000 & $5 \times 10^{-6}$ & 0.020 & 0 & 625 & 0.032 & 0.29 & 0.42 \\
$\mathbf{D E R}_{3}$ & D-ICE & & & & & & & & \\
\hline
\end{tabular}

does not generate active power, the price of DER buses becomes equal to the market price at $20(\$ / \mathrm{MW})$. The results of this problem are shown in the first row of Table 6 .

Furthermore, as shown in Table 5, as the market price increases, the DER's power also increases. For example, in case of the market price being equal to $28(\$ / \mathrm{MW})$, DER1 generates $753.74 \mathrm{~kW}$; in case of the market price being equal to $26(\$ / \mathrm{MW}), 588.595$ $\mathrm{kW}$ is generated. When the market price is equal to 30 (\$/MW), DER2, DER3, and DER4 generate the active power of $1000 \mathrm{~kW}$. Due to the constraint of DER 
Table 4. The pseudo codes of MOPSO [33], MOPSO-FDR, MOGA [34], and NSGA-II [35].

\begin{tabular}{|c|c|c|c|}
\hline Initialize & $\begin{array}{l}\text { (a) MOPSO } \\
\text { Swarm positions, velocities and } \\
\text { leaders. } \\
\text { Send leader to archive } \\
\text { Crowding (leaders), } g=0\end{array}$ & Initialize & $\begin{array}{l}\text { (b) MOPSO-DFR } \\
\text { swarm positions, velocities and } \\
\text { leaders. } \\
\text { Send leader to archive } \\
\text { Crowding (leaders), } g=0\end{array}$ \\
\hline While & $g<g \max$ & Set & $\begin{array}{l}\text { Initial leaders of the EA } \\
\text { Evaluate leaders according to DF } \\
\text { and CD }\end{array}$ \\
\hline For & $\begin{array}{l}\text { Each particle } \\
\text { select leader. } \\
\text { Update position (flight) and } \\
\text { velocities } \\
\text { Mutation. } \\
\text { Evaluate fitness. }\end{array}$ & While & $g<g \max$ \\
\hline End For & 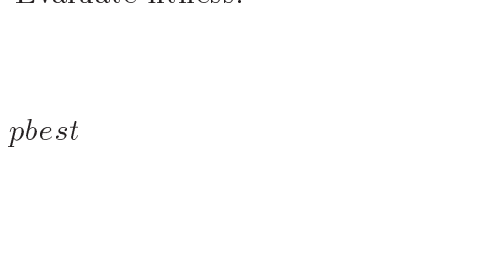 & For & $\begin{array}{l}\text { Each particle } \\
\text { select leader. } \\
\text { Select social leaders according to } \\
\text { DF and CD using roulette } \\
\text { Update position (flight) and } \\
\text { velocities } \\
\text { Mutation. } \\
\text { Evaluate fitness }\end{array}$ \\
\hline End For & gbest (leaders) & & \\
\hline Update & $\begin{array}{l}\text { Send leaders to archive. } \\
\text { Crowding (leaders), } g=g+1\end{array}$ & & \\
\hline End While & & Update & $\begin{array}{l}\text { cognitive memory using CD } \\
\text { pbest }\end{array}$ \\
\hline End & Report results in archive & End For & $\begin{array}{l}\text { gbest (leaders) from } E A \\
\text { Send leaders to archive. } \\
\text { Crowding (leaders), } g=g+1 \\
\text { Sort and prune } E A \text { according to } D F \\
\text { Evaluate leaders according to } D F \\
\text { and } C D\end{array}$ \\
\hline & & $\begin{array}{l}\text { End While } \\
\text { End }\end{array}$ & Report results in archive \\
\hline Initialize & $\begin{array}{l}\text { (c) MOGA } \\
\text { Population } \\
\text { Evaluate Objective Values } \\
\text { Assign Rank Based on Pareto } \\
\text { DominanceCompute Niche Count } \\
\text { Assign Linearly Scaled Fitness } \\
\text { Assign Shared Fitness }\end{array}$ & Proced ure & NSGA-II special function \\
\hline For & $\begin{array}{l}g=1 \text { to number of Generations } \\
\text { Selection via Stochastic Universal } \\
\text { Sampling } \\
\text { Single Point Crossover } \\
\text { Mutation } \\
\text { Evaluate Objective Values } \\
\text { Assign Rank Based on Pareto } \\
\text { Dominance } \\
\text { Compute Niche Count } \\
\text { Assign Linearly Scaled Fitness } \\
\text { Assign Shared Fitness }\end{array}$ & Initialize & $\begin{array}{l}\text { Population } P^{\prime} \\
\text { Generate random population } N^{\prime} \\
\text { Evaluate Objective Values } \\
\text { Assign Rank Based on Pareto } \\
\text { Dominance } \\
\text { Generate Child Population } \\
\text { Binary Tournament Selection } \\
\text { Recombination and Mutation }\end{array}$ \\
\hline & & For & $i=\operatorname{tog}$ \\
\hline End & & For & $\begin{array}{l}\text { Each parent and child in } \\
\text { population } \\
\text { assign rank (level) based on } \\
\text { Pareto } \\
\text { Generate sets of non-dominated } \\
\text { vectors }\end{array}$ \\
\hline & & $\begin{array}{l}\text { End For } \\
\text { End }\end{array}$ & $\begin{array}{l}\text { Select points (elitist) on the lower } \\
\text { front (with lower rank) and are } \\
\text { outside a crowding distance } \\
\text { Create next generation } \\
\text { Binary tournament selection } \\
\text { Recombination and mutation }\end{array}$ \\
\hline
\end{tabular}




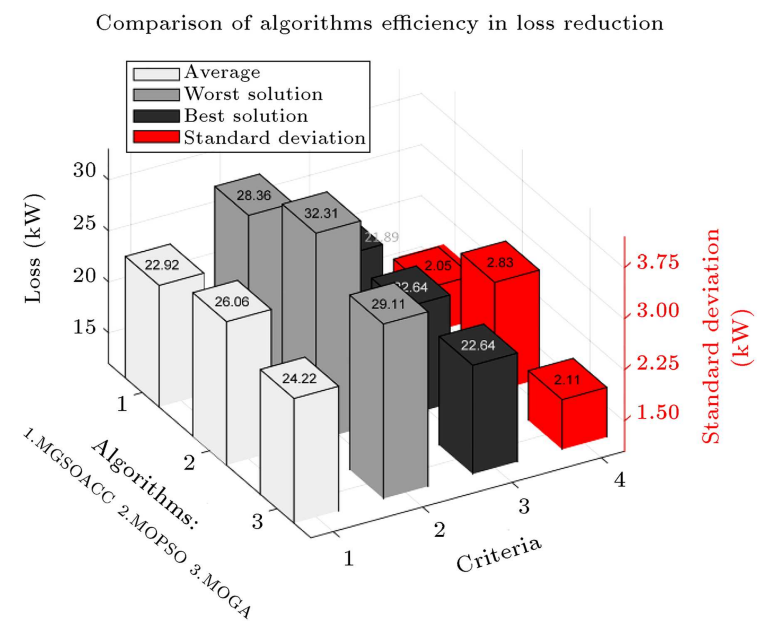

(a)

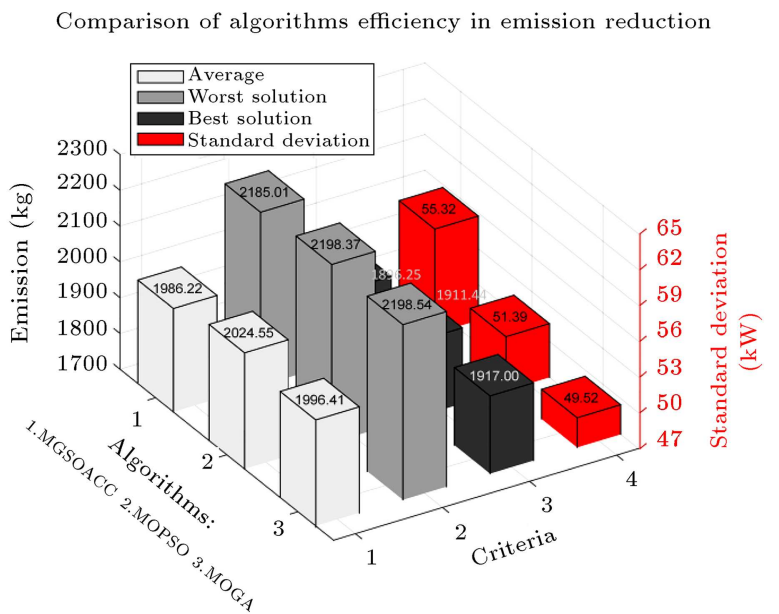

(b)

Figure 5. Comparison of MOGA, MOPSO, and MGSOACC Algorithms in terms of optimizing the objectives for IEEE 33-bus network: (a) Loss optimization and (b) emission optimization.

Comparison of algorithms efficiency in loss reduction

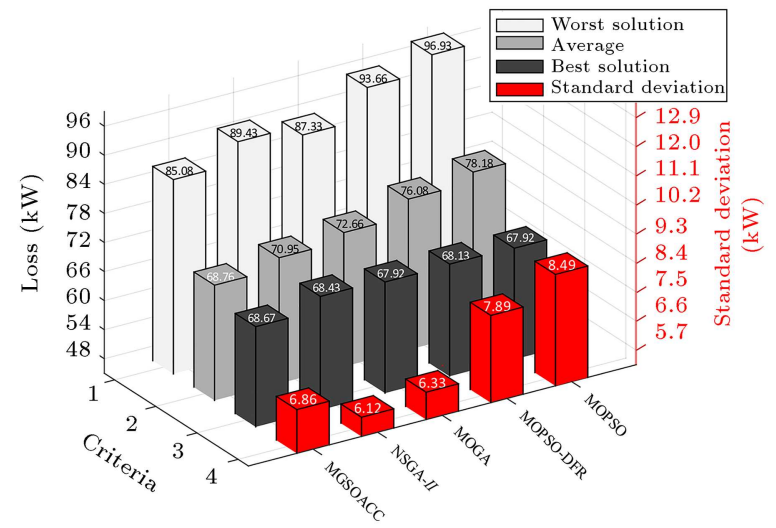

(a)
Comparison of algorithms efficiency in emission reduction

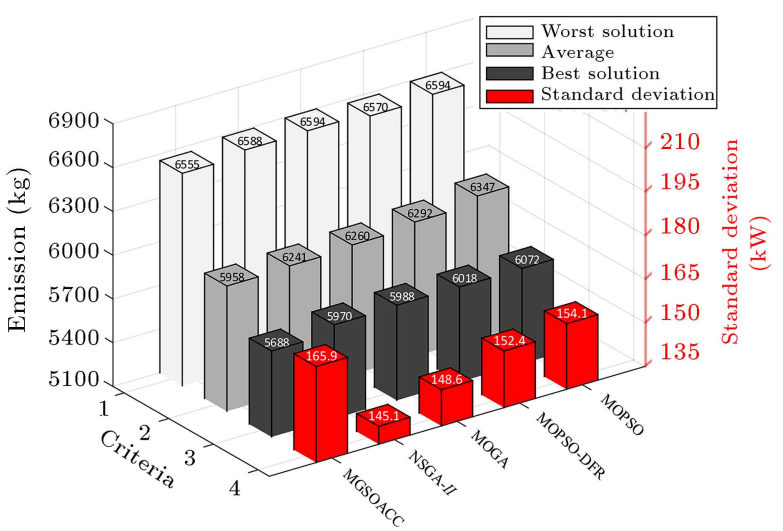

(b)

Figure 6. Comparison of MOPSO, MOPSO-FDR, MOGA, NSGA-II, and MGSOACC algorithms in terms of optimizing the objectives for IEEE 33-bus network: (a) Loss optimization and (b) emission optimization.

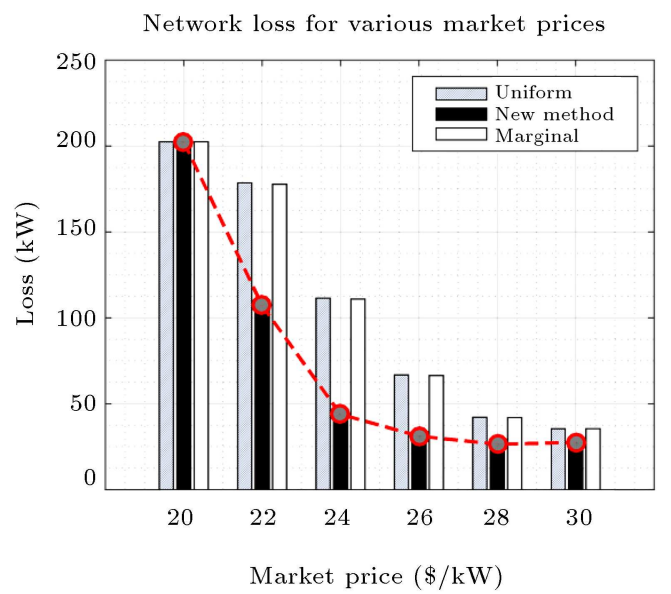

(a)

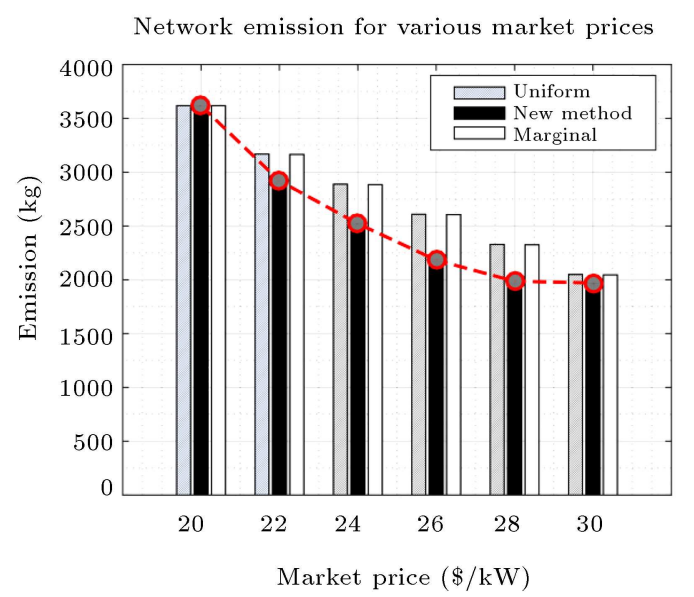

(b)

Figure 7. Loss and emission of network for various market prices: (a) Loss and (b) emission. 
Table 5. Nodal prices of Distributed Energy Resource (DER) units vs market prices.

\begin{tabular}{|c|c|c|c|c|c|c|c|c|c|c|c|c|}
\hline \multirow{2}{*}{ 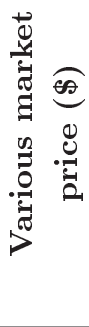 } & \multicolumn{3}{|c|}{$\begin{array}{c}\text { Nodal price } \\
\text { of } \operatorname{DER}_{1}(\$ / k W)\end{array}$} & \multicolumn{3}{|c|}{$\begin{array}{l}\text { Nodal price of } \\
\operatorname{DER}_{2}(\$ / \mathrm{kW})\end{array}$} & \multicolumn{3}{|c|}{$\begin{array}{l}\text { Nodal price of } \\
\operatorname{DER}_{3}(\$ / \mathrm{kW})\end{array}$} & \multicolumn{3}{|c|}{$\begin{array}{l}\text { Nodal price of } \\
\mathrm{DER}_{4}(\$ / \mathrm{kW})\end{array}$} \\
\hline & 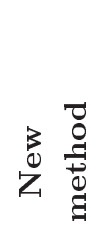 & 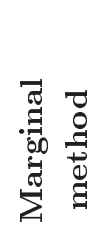 & 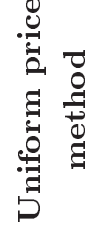 & 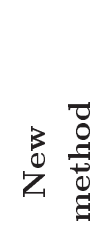 & 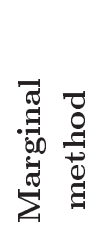 & 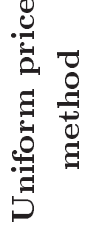 & 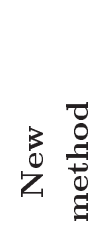 & 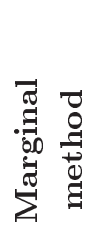 & 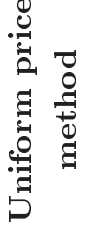 & Z & 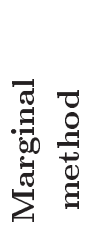 & 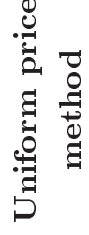 \\
\hline 20 & 20 & 20 & 20 & 20 & 20 & 20 & 20 & 20 & 20 & 20 & 20 & 20 \\
\hline 22 & 22.451 & 22.011 & 22 & 26.112 & 22 & 22 & 22.952 & 22.29 & 22 & 23.932 & 22.81 & 22 \\
\hline 24 & 26.225 & 25.13 & 24 & 27.647 & 24 & 24 & 25.887 & 24.20 & 24 & 28.027 & 24.32 & 24 \\
\hline 26 & 29.854 & 26.700 & 26 & 30.882 & 26.750 & 26 & 29.638 & 26.36 & 26 & 28.128 & 26.08 & 26 \\
\hline 28 & 29.147 & 28.57 & 28 & 31.643 & 28.56 & 28 & 30.947 & 28.25 & 28 & 31.658 & 28.03 & 28 \\
\hline 30 & 30.449 & 30.026 & 30 & 32.102 & 30.73 & 30 & 32.961 & 30.10 & 30 & 33.066 & 30.10 & 30 \\
\hline
\end{tabular}

Table 6. Generation of Distributed Energy Resource (DER) units vs market prices.

\begin{tabular}{|c|c|c|c|c|c|c|c|c|c|c|c|c|}
\hline \multirow{2}{*}{ 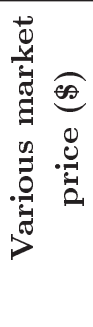 } & \multicolumn{3}{|c|}{$\begin{array}{l}\text { Generation of } \\
\operatorname{DER}_{1}(\$ / \mathrm{kW})\end{array}$} & \multicolumn{3}{|c|}{$\begin{array}{l}\text { Generation of } \\
\mathrm{DER}_{2}(\$ / \mathrm{kW})\end{array}$} & \multicolumn{3}{|c|}{$\begin{array}{l}\text { Generation of } \\
\mathrm{DER}_{3}(\$ / \mathrm{kW})\end{array}$} & \multicolumn{3}{|c|}{$\begin{array}{l}\text { Generation of } \\
\operatorname{DER}_{4}(\$ / \mathrm{kW})\end{array}$} \\
\hline & z & 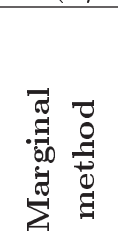 & 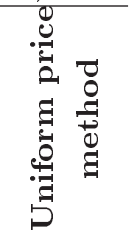 & 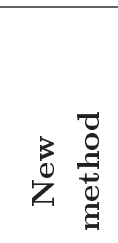 & 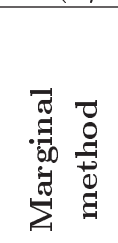 & 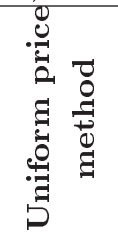 & 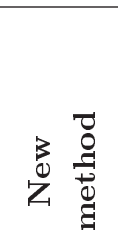 & 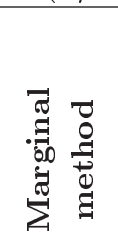 & 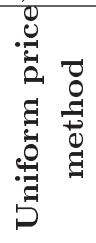 & 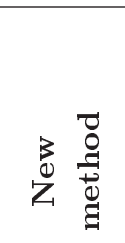 & 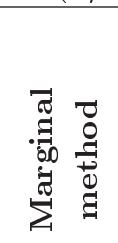 & 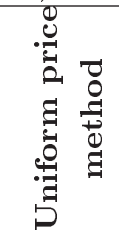 \\
\hline 20 & 0 & 0 & 0 & & & 0 & 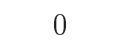 & & & & & . \\
\hline 22 & 103.545 & .586 & 6.20 & .521 & 79 & 88.6 & 9.367 & 20 & 20 & 5.006 & 8 & 36.2069 \\
\hline 24 & 475.491 & 3.751 & 258.620 & .554 & 381.563 & 377.358 & 6.743 & 403.950 & 40 & 221 & 260.400 & 258.620 \\
\hline 26 & 591.018 & 435.125 & 431.034 & 933.695 & 569.078 & 566.037 & 702.478 & 604 & 600 & 746.149 & 435.785 & 431.034 \\
\hline 28 & 756.244 & 7.450 & 603.448 & 1000 & 757.726 & 754.717 & 1000 & 802 & 800 & 87.985 & 604.568 & 603.448 \\
\hline 30 & 36.022 & 79.874 & 775.862 & 1000 & 946.396 & 43.396 & 1000 & 100 & 1000 & 1000 & 776.862 & 775.862 \\
\hline
\end{tabular}

capacity, they can produce up to $1000 \mathrm{~kW}$; however, through Eq. (17), the generation of DERs is calculated at more than $1000 \mathrm{~kW}$ and DERs are forced to generate the maximum capacity of active power. If the capacity of DER increases, greater power can be reached in the intended market price.

Figure 4 shows the optimized value of emission and loss for various suggested market prices. As shown in Table 5, as the market price increases, the loss and emission in all pricing methods increase. Thus, the proposed method achieves greater reduction than methods of uniform price and marginal loss.

Reduction of these objectives causes extra benefits for DISCO. This benefit is equal to $1 \mathrm{MW}$ power and $1 \mathrm{~kg}$ emission costing $1 \$$ and $5.94 \$$, respectively. These values are $\lambda_{1}$ and $\lambda_{2}$ in simulation, respectively. Based on the allowance price of emission and market price, decreasing these objectives follows an identical cost incurred on DISCO. Also, DISCO allocates the benefit of loss and emission reduction to DERs to generate more active power and aims to reduce loss and emission of the distribution network. DERs need much capital to generate extra power and DISCO supplies the required amount of capital to generate more active power of DERs.

Moreover, DERs being far away from the substation have greater impact on their generation than other DERs due to the overall system loss reduction. This trend can be seen in DERs located at buses 12 and 9 in the IEEE 32-bus test system. In addition, in a similar way, in IEEE 69-bus test system, DERs located at Buses 27, 35, 46, and 64 have a greater impact on loss reduction than the other ones.

However, such an argument does not hold for 
the impact of each DER on reducing emission. This amount may vary depending on the generation capacity and the emission coefficients of each one.

\subsection{The non-inferior solutions}

As the generation of DERs active power increases, the allocated cost to DERs increases consequently.

In the case of the multi-objective problem, a unique solution that can be both optimal and allencompassing does not exist; besides, the solutions constitute a set called non-inferior solutions. This process is presented as follows [23]:

Pareto dominance: $A<B$ if and only if:

$$
\begin{cases}f_{i}(A) \leq f_{i}(B), \quad \forall i \in\{1,2, \ldots, m\} \\ f_{i}(A)<f_{i}(B), \quad \forall i \in\{1,2, \ldots, m\}\end{cases}
$$

Pareto optimal: solution $A$ is Pareto if and only if:

$$
! \exists X \in R^{n}: X \prec A .
$$

The Pareto optimal set contains the Pareto optimal solutions and the area contained by all non-inferior objective vectors is called Pareto front.

By solving the proposed multi-objective problem, the Pareto optimal solutions are obtained. Consequently, the best-comprised solution of Pareto should be selected for the proposed problem. In this regard, the max-min fuzzy satisfying criterion is employed to select the best-comprised solution. In this method, first, the Fuzzy Membership Functions (FMFs) are measured. This procedure can be mathematically expressed as follows:

$$
\phi_{q, z}=\left\{\begin{array}{cc}
1 & f_{q, z}<f_{q}^{\min } \\
f_{q}^{\max }-f_{q, z} & f_{q}^{\min }<f_{q, z}<f_{q}^{\max } \\
f_{q}^{\max }-f_{q}^{\text {min }} & f_{q, z}>f_{q}^{\max }
\end{array}\right\},
$$

$$
\forall q \in \Phi, z \in S,
$$

where $z$ refers to the $z$ th solution of the $q$ th objective function. $f_{q}^{\max }$ is the membership objective function with the maximum value of $f_{q}$ calculated for the minimum value of $f_{q^{\prime}}$, which is in conflict with $f_{q}$, i.e., $q^{\prime} \in \Phi-q$. This means that the maximum value of $f_{q}$ is obtained when $f_{q^{\prime}}$ is optimally minimized. Generally, the values of $f_{q}^{\min }$ and $f_{q}^{\max }$ are obtained for the optimization of the $q$ th objective function in a single objective problem, separately. Therefore, the maximum value of overall satisfaction is obtained as the best comprised solution as follows:

$$
\Theta=\max _{\forall z \in S}\left\{\min _{\forall q \in \Phi}\left\{\phi_{q, z}\right\}\right\} \text {. }
$$

In a multi-objective optimization problem, the concept of optimality is replaced by a non-dominated solution (Pareto optimality). A general multi-objective optimization problem can be formulated as follows:

Minimize

$$
F=\left[f_{1}(X), f_{2}(X), \ldots, f_{N_{o b j}}(X)\right],
$$

where $X$ is a feasible solution, $f_{i}(X)$ is the $i$ th objective function, and $N_{o b j}$ is the number of objective functions.

For any two solutions $X_{1}$ and $X_{2}$, the solution $X_{1}$ dominates $X_{2}$ if the following two conditions are satisfied:

$$
\left\{\begin{array}{l}
\forall m \in\left\{1,2, \ldots, N_{o b j}\right\}, f_{m}\left(X_{1}\right) \leq f_{m}\left(X_{2}\right) \\
\exists n \in\left\{1,2, \ldots, N_{o b j}\right\}, f_{n}\left(X_{1}\right)<f_{n}\left(X_{2}\right)
\end{array}\right.
$$

If any of the conditions are unacceptable, $X_{1}$ cannot dominate $X_{2}$; otherwise, $X_{1}$ dominates $X_{2}$, hence a non-dominated solution.

The Pareto front of the LMP problem solved by MGSOACC algorithm is presented in Figure 8 . According to the figure, non-inferior solutions are reasonable. The solution with a larger membership function value is chosen the best solution to the multiobjective optimization problem in the search process of MGSOACC algorithm. This selection is based on the allowance price of $1 \mathrm{~kg}$ emission and market price. The price of $1 \mathrm{~kg}$ emission is higher than that of $1 \mathrm{MW}$ loss, and the reduction of emission brings about more benefits, including more money to DISCO, than the reduction of loss.

\section{Conclusion}

In order to solve the optimization problem due to loss/emission reduction in the distribution networks, a multi-objective group search optimizer with adaptive covariance matrix and chaotic search was given in the presence of Distributed Energy Resources (DERs) in accordance with the suggested market prices.

The simulation results confirmed that DER generations were directly related to the suggested price of the bus installed on it. Moreover, the performance of the proposed method seems to be appropriate and effective in the simultaneous reduction of two technical objectives: loss and emission. This method reduces loss and emission by $87 \%$ and $44 \%$ in the IEEE $33-$ bus network, respectively, and by $89 \%$ and $21 \%$ in the IEEE 69-bus network, respectively.

The application of the game-theoretic method as a guarantee of the fairness in the case of the incentive allocation method helps make the proposed method more effective.

Comparison of algorithms proves that the proposed optimization method has a better performance than the other optimization methods, including MOPSO, MOPSO-FDR, MOGA, and NSGA-II, 


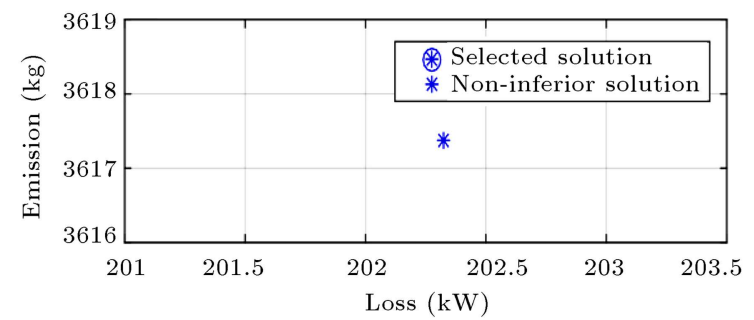

(a) Market price $=20(\$ / \mathrm{kW})$

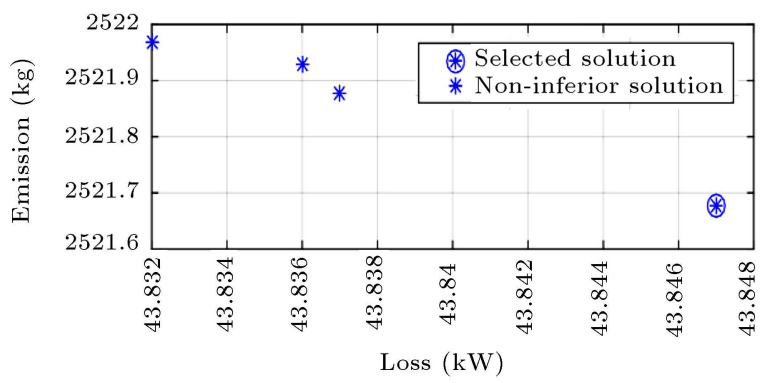

(c) Market price $=24(\$ / \mathrm{kW})$

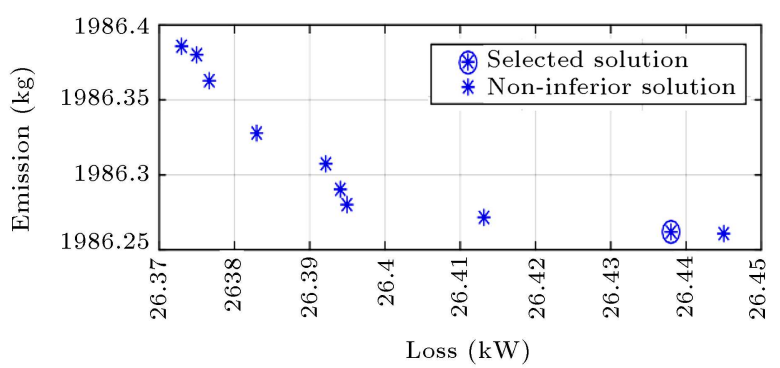

(e) Market price $=28(\$ / \mathrm{kW})$

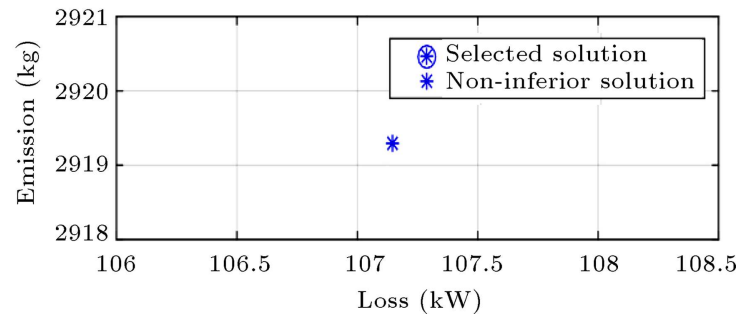

(b) Market price $=22(\$ / \mathrm{kW})$

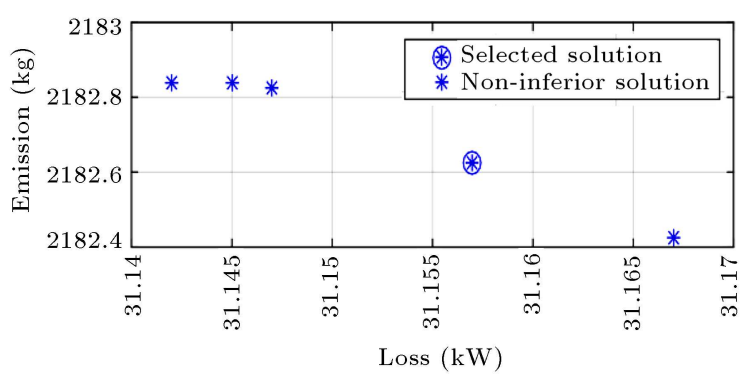

(d) Market price $=26(\$ / \mathrm{kW})$

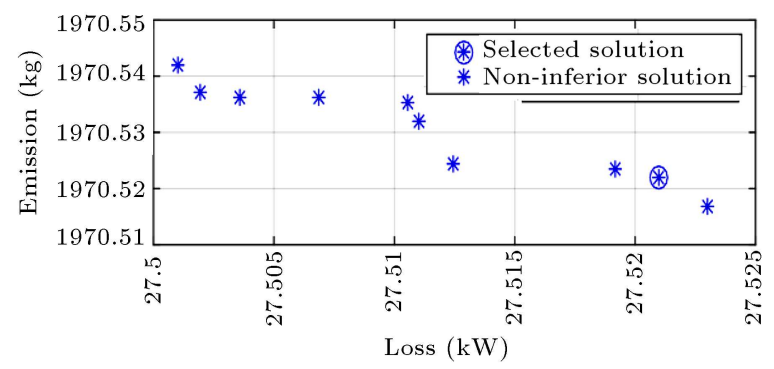

(f) Market price $=30(\$ / \mathrm{kW})$

Figure 8. Obtained non-inferior solution using MGSOACC algorithm for different market prices when objectives are power loss and emission reduction.

in terms of the worst, average, and best solutions. However, in terms of standard deviation, this method is slightly worse than optimization methods.

The suggested method, which is based on the non-inferior solution, is more efficient than the other conventional multi-objective approaches.

Because these several non-inferior solutions allow decision-makers to select the best solution according to various behaviors of network objectives in the loss/emission reduction procedure, depending on the network behavior in the decision-making process, the share of benefits allocated to each objective can be reduced or increased.

Furthermore, the simulation results prove that the proposed method is a reliable answer to the distribution pricing problem.

\section{Nomenclature}

AER

Allocated contribution to participation due to emission reduction

ALR
Allocated contribution to participation due to loss reduction $b$

$C_{i}$

$C^{L}$

$C^{R}$

CCGT

$\mathrm{CO}$

$\mathrm{CO}_{2}$

$\delta_{i}$

DER

D-ICE

DISCO

$\varepsilon$

$E_{D G, i}$

emission $^{\text {base }}$

$\phi_{i}(v)$

$\gamma_{t}$

G-ICE
The $b$ branch

Interval number

Lower bounds of the objective interval

Upper bounds of the objective interval Combined Cycle Gas Turbines

Carbon monoxide

Carbon dioxide

The angle of bus voltage

Distributed Energy Resource

Diesel Internal Combustion Engines

Distribution Company

Maximum deviation of the MS

The emission produced by the main bus

The emission of network without DER units participation

Shapley value function for player $i$

The emission allowance price

Gas internal combustion engines 


\begin{tabular}{|c|c|}
\hline$I_{b r}$ & Current of the branch \\
\hline$\lambda$ & Market price \\
\hline loss ${ }^{\text {base }}$ & $\begin{array}{l}\text { The losses of network without DER } \\
\text { units participation }\end{array}$ \\
\hline$m$ & Midpoint of interval \\
\hline$\mu$ & Control parameter \\
\hline MOGA & Multi-Objective Genetic Algorithm \\
\hline MOPSO & $\begin{array}{l}\text { Multi-Objective Particle Swarm } \\
\text { Optimization }\end{array}$ \\
\hline MOPSO-FDR & $\begin{array}{l}\text { Multi-Objective Particle Swarm } \\
\text { Optimization using Diversity Factor } \\
\text { and Roulette Wheel }\end{array}$ \\
\hline NSGA & $\begin{array}{l}\text { Non-dominated Sorting Genetic } \\
\text { Algorithm }\end{array}$ \\
\hline$M S$ & Maximum deviation of the MS \\
\hline$N_{b r}$ & Total number of branches \\
\hline$N_{D E R}$ & Number of DERs \\
\hline$N O x$ & Oxides of nitrogen family \\
\hline$P_{i}$ & Net injected active power \\
\hline$P_{D E R, i}$ & Active power of $i$ th DER \\
\hline$P_{\text {loss }}$ & Active power losses \\
\hline$P_{\min , D E R, i}$ & Minimum active power of $i$ th DER \\
\hline$p f_{i}$ & Power factor of $i$ th DER \\
\hline$p f_{\max , i}$ & Maximum power factor \\
\hline$P f_{\min , i}$ & Minimum power factor \\
\hline$\pi_{i}$ & LMP at the DER connected busses \\
\hline$\pi^{a}$ & $\begin{array}{l}\text { Active power price at DER connected } \\
\text { busses }\end{array}$ \\
\hline$\pi^{r}$ & $\begin{array}{l}\text { Reactive power price at DER connected } \\
\text { busses }\end{array}$ \\
\hline$Q_{i}$ & Net injected reactive power \\
\hline$Q_{D E R, i}$ & Reactive power of $i$ th DER \\
\hline$Q_{\min , D E R, i}$ & Minimum reactive power of $i$ th DER \\
\hline$Q_{\max , D E R, i}$ & Maximum reactive power of $i$ th DER \\
\hline$R_{b r}$ & Resistance of the branch \\
\hline$|S|$ & Coalition index \\
\hline $\mathrm{SO}_{2}$ & Oxides of sulphur family \\
\hline$\tau$ & Radius of interval \\
\hline$\theta_{i j}$ & $\begin{array}{l}\text { The angle of the admittance between } \\
i \text { th and } j \text { th buses }\end{array}$ \\
\hline$U$ & Vectors of interval variables \\
\hline$u^{(g)}$ & Chaotic sequence elements \\
\hline$U^{L}$ & Upper bounds of the interval variables \\
\hline$U^{R}$ & Lower bounds of the interval variables \\
\hline$V_{i}$ & The amplitude of bus voltage \\
\hline$v_{l}(s)$ & $\begin{array}{l}\text { Function of reduced loss via coalition } \\
S\end{array}$ \\
\hline$v_{l}(s)-v_{l}(s-d)$ & $\begin{array}{l}\text { Function of reduced loss via coalition } \\
S \text { without } D G_{d}\end{array}$ \\
\hline
\end{tabular}

\begin{tabular}{|c|c|}
\hline$v_{e}(s)$ & $\begin{array}{l}\text { Function of reduced emission via } \\
\text { coalition } S\end{array}$ \\
\hline \multicolumn{2}{|c|}{$\begin{array}{c}v_{e}(s)-v_{e}(s-d) \text { Function of reduced emission via } \\
\text { coalition } S \text { without } D G_{d}\end{array}$} \\
\hline$\omega_{e}$ & $\begin{array}{l}\text { Share of DER units from mitigating } \\
\text { the emission allowance to the DISCO }\end{array}$ \\
\hline$X$ & Vectors of independent variables \\
\hline$x_{i}^{(g)}$ & Position of the $i$ th ranger \\
\hline$\wp_{i}$ & Pareto-optimal solution \\
\hline$Y$ & Vectors of dependent variables \\
\hline$Y_{i j}$ & $\begin{array}{l}\text { The amplitude of the admittance } \\
\text { between the } i \text { th and } j \text { th buses }\end{array}$ \\
\hline
\end{tabular}

\section{References}

1. Zhang, D., Li, M., Ji, X., Wu, J., and Dong, Y. "Revealing potential of energy-saving behind emission reduction", Management of Environmental Quality: An International Journal, 30(4), pp. 714-730 (2018).

2. Karasoy, A. and Akçay, S. "Effects of renewable energy consumption and trade on environmental pollution", Management of Environmental Quality: An International Journal, 30(2), pp. 437-455 (2019).

3. Pavani, P. and Singh, S.N. "Placement of DG for reliability improvement and loss minimization with reconfiguration of radial distribution systems", International Journal of Energy Sector Management, 8(3), pp. 312-329 (2014).

4. Lorestani, A., Gharehpetian, G.B., and Nazari, M.H. "Optimal sizing and techno-economic analysis of energy- and cost-efficient standalone multi-carrier microgrid", Energy, 178, pp. 751-764 (2019).

5. Lorestani, A., Mohammadian, M., Aghaee, S.S., et al. "A novel analytical-heuristic approach for placement of multiple distributed generator in distribution network", 2016 Smart Grids Conference (SGC), IEEE, pp. 1-7 (2016).

6. Ahmadi, P., Nazari, M.H., and Hosseinian, S.H. "Optimal resources planning of residential complex energy system in a day-ahead market based on invasive weed optimization algorithm", Engineering, Technology \& Applied Science Research, 7(5), pp. 1934-1939 (2017).

7. Nazari, M.H., Hosseinian, S.H., and Azad-farsani, E. "A multi-objective LMP pricing strategy in distribution networks based on MOGA algorithm", Journal of Intelligent \& Fuzzy Systems, 36(6), pp. 6143-6154 (2019).

8. Azad-Farsani, E. "Loss minimization in distribution systems based on LMP calculation using honey bee mating optimization and point estimate method", Energy, 140, pp. 1-9 (2017).

9. Alkaabi, S.S., Zeineldin, H.H., and Khadkikar, V. "Short-term reactive power planning to minimize cost of energy losses considering PV systems", IEEE Transactions on Smart Grid, 10(3), pp. 2923-2935 (2019). 
10. Savelli, I., Giannitrapani, A., Paoletti, S., and Vicino, A. "An optimization model for the electricity market clearing problem with uniform purchase price and zonal selling prices", IEEE Transactions on Power Systems, 33(3), pp. 2864-2873 (2018).

11. Ding, F. and Fuller, J.D. "Nodal, uniform, or zonal pricing: distribution of economic surplus", IEEE Transactions on Power Systems, 20(2), pp. 875-882 (2005).

12. Liu, L. and Zobian, A. "The importance of marginal loss pricing in an RTO environment", The Electricity Journal, 15(8), pp. 40-45 (2002).

13. Huang, S., Wu, Q., Oren, S.S., Li, R., and Liu, Z. "Distribution locational marginal pricing through quadratic programming for congestion management in distribution networks", IEEE Transactions on Power Systems, 30(4), pp. 2170-2178 (2015).

14. ISO New England Inc., ISO New England Manual for Market Operations, ISO-NE PUBLIC, Revision 57 (2019).

15. Yang, Z., Bose, A., Zhong, H., Zhang, N., Lin, J., Xia, Q., and Kang, C. "LMP revisited: A linear model for the loss-embedded LMP", IEEE Transactions on Power Systems, 32(5), pp. 4080-4090 (2017).

16. Hosseinian, S.H., Askarian-Abyaneh, H., AzadFarsani, E., and Abedi, M. "Stochastic locational marginal price calculation in distribution systems using game theory and point estimate method", IET Generation, Transmission \& Distribution, 9(14), pp. 1811-1818 (2015).

17. Sotkiewicz, P.M. and Vignolo, J.M. "Nodal pricing for distribution networks: efficient pricing for efficiency enhancing DG", IEEE Transactions on Power Systems, 21(2), pp. 1013-1014 (2006).

18. Morais, H., Faria, P., and Vale, Z. "Demand response design and use based on network locational marginal prices", International Journal of Electrical Power \& Energy Systems, 61, pp. 180-191 (2014).

19. Farsani, E.A., Abyaneh, H.A., Abedi, M., and Hosseinian, S.H. "A novel policy for LMP calculation in distribution networks based on loss and emission reduction allocation using nucleolus theory", IEEE Transactions on Power Systems, 31(1), pp. 143-152 (2016).

20. Wei, Y., and Yanli, W. "Advanced Studies on Locational Marginal Pricing”, Doctoral Dissertations, Tennessee Research, and Creative Exchange, University of Tennessee (2013).

21. Sarafraz, F., Ghasemi, H., and Monsef, H. "Locational marginal price forecasting by locally linear neuro-fuzzy model", 10th International Conference on Environment and Electrical Engineering, IEEE, pp. 1-4 (2011).

22. Khodadadi, A., Hasanpor Divshali, P., Nazari, M.H., and Hosseinian, S.H. "Small-signal stability improvement of an islanded microgrid with electronicallyinterfaced distributed energy resources in the presence of parametric uncertainties", Electric Power Systems Research, 160, pp. 151-162 (2018).
23. Wang, L., Zhong, X., and Liu, M. "A novel group search optimizer for multi-objective optimization", Expert Systems with Applications, 39(3), pp. 29392946 (2012).

24. Özceylan, E., Kabak, M., and Dă̆deviren, M. "A fuzzy-based decision making procedure for machine selection problem", Journal of Intelligent \& Fuzzy Systems, 30(3), pp. 1841-1856 (2016).

25. Galiana, F.D. and Khatib, S.E. "Emission allowances auction for an oligopolistic electricity market operating under cap-and-trade", IET Generation, Transmission \& Distribution, 4(2), p. 191 (2010).

26. Farsani, E.A., Abyaneh, H.A., Abedi, M., and Hosseinian, S.H. "A novel policy for LMP calculation in distribution networks based on loss and emission reduction allocation using Nucleolus theory", IEEE Transactions on Power Systems, 31(1), pp. 143-152 (2016).

27. Wu, Q.H., Lu, Z., Li, M.S., and Ji, T.Y. "Optimal placement of FACTS devices by a group search optimizer with multiple rpoducer", 2008 IEEE Congress on Evolutionary Computation (IEEE World Congress on Computational Intelligence), IEEE, pp. 1033-1039 (2008).

28. Hansen, N., Müller, S.D., and Koumoutsakos, P. "Reducing the time complexity of the derandomized evolution tsrategy with covariance matrix adaptation (CMA-ES)", Evolutionary Computation, 11(1), pp. 118 (2003).

29. Peng, J. and Jiang, H. "Fair and analytical allocating of transmission losses using two-step coalitional game", IEEE Power Engineering Society General Meeting, Denver (2004).

30. Peng, J.-C., Jiang, H., and Song, Y.-H. "A weakly conditioned imputation of an impedance-branch dissipation power", IEEE Transactions on Power Systems, 22(4), pp. 2124-2133 (2007).

31. Sharma, S. and Abhyankar, A. "Loss allocation for weakly meshed distribution system using analytical formulation of shapley value", IEEE Transactions on Power Systems, 32(2), pp. 1369-1377 (2016).

32. Wei, F., Wu, Q.H., Jing, Z.X., Chen, J.J., and Zhou, X.X. "Optimal unit sizing for small-scale integrated energy systems using multi-ob jective interval optimization and evidential reasoning approach", Energy, 111, pp. 933-946 (2016).

33. Hosseini, S.J.al-D., Moradian, M., Shahinzadeh, H., and Ahmadi, S. "Optimal placement of distributed generators with regard to reliability -assessment using virus colony search algorithm", International Journal of Renewable Energy Research (IJRER), 8(2), pp. 714723 (2018).

34. Nazari, M.H., Khodadadi, A., Lorestani, A., Hosseinian, S.H., and Gharehpetian, G.B. "Optimal multiobjective D-STATCOM placement using MOGA for THD mitigation and cost minimization", Journal of Intelligent \& Fuzzy Systems, 35(2), pp. 2339-2348 (2018). 
35. Coello Coello, C.A., Veldhuizen, D.A., and Lamont, G.B., Evolutionary Algorithms for Solving MultiObjective Problems, Springer US (2002).

36. Abdolahi, A., Salehi, J., Samadi Gazijahani, F., and Safari, A. "Probabilistic multi-objective arbitrage of dispersed energy storage systems for optimal congestion management of active distribution networks including solar/wind/CHP hybrid energy system", Journal of Renewable and Sustainable Energy, 10(4), p. 045502 (2018).

37. Zheng, J.H., Chen, J.J., Wu, Q.H., and Jing, Z.X. "Multi-objective optimization and decision making for power dispatch of a large-scale integrated energy system with distributed DHCs embedded", Applied Energy, 154, pp. 369-379 (2015).

38. Deb, K., Pratap, A., Agarwal, S., and Meyarivan, T. "A fast and elitist multiobjective genetic algorithm: NSGA-II", IEEE Transactions on Evolutionary Computation, 6(2), pp. 182-197 (2002).

\section{Biographies}

Mohammad Hassan Nazari was born in Iran. He received the MS degree in Electrical Engineering from Sharif University of Technology, Tehran, Iran in 2013. Currently, he is pursuing the PhD degree in Electrical Engineering at Amirkabir University of Technology (AUT), Tehran, Iran. His research interests include techno-economic techniques in power market, power quality, smart grids, optimization methods, and evolutionary algorithms.
Seyed Hossein Hosseinian was born in Iran. He received the PhD degree from the Electrical Engineering Department, University of Newcastle, Newcastle upon Tyne, U.K. in 1995. At present, he is a Professor at the Electrical Engineering Department at Amirkabir University of Technology (AUT), Tehran, Iran. His special fields of interest include transient in power systems, power quality, restructuring, and deregulation in power systems. He is the author of four books in the field of power systems. He is also the author and the coauthor of over 300 technical papers.

Ehsan Azad Farsani was born in Farsani, Iran. He received $\mathrm{PhD}$ degree in Electrical Engineering from the Amirkabir University of Technology, Tehran, Iran in 2014. Currently, he is an Assistant Professor in Electrical Engineering at Golpayegan University of Technology, Isfahan, Iran. His research interests include power market, smart grids, stochastic electric power system planning, optimization methods, and evolutionary algorithms.

Davood Faramarzi was born in Iran. He received the BS and MS degrees in Electrical Engineering from Amirkabir University of Technology (AUT), Tehran, Iran in 2014 and 2016, respectively. Currently, he is pursuing the $\mathrm{PhD}$ degree in Electrical Engineering at Amirkabir University of Technology (AUT), Tehran, Iran. His research interests include smart grid management and resilience of power systems. 